\title{
GAMBARAN SIKAP KEWIRAUSAHAAN DAN NIAT BERWIRAUSAHA PADA MAHASISWI ANGKATAN 2014 DI UPI BANDUNG
}

\author{
Widiana Rahayu \\ Universitas Pendidikan Indonesia \\ widiana.rahayu94@student.upi.edu \\ Hari Mulyadi \\ Universitas Pendidikan Indonesia \\ Harimulyadi@upi.edu \\ Rd. Dian H. Utama \\ Universitas Pendidikan Indonesia \\ Dhutama@upi.edu
}

\begin{abstract}
ABSTRAK
Tujuan - Tujuan dari penelitian ini adalah untuk mengetahui gambaran dimensi sikap kewirausahaan dan niat berwirausaha.

Desain/Metodologi/Pendekatan - Desain penelitian ini adalah cross sectional dengan menggunakan pendekatan deskriptif melalui metode explanatory survei. Unit analisis mahasiswi sebanyak 145 responden. Sebuah angket digunakan sebagai instrumen penelitian untuk mengumpulkan data dari responden. Teknik analisis yang digunakan adalah teknik deskriptif dengan menggunakan distribusi frekuensi.

Temuan - Berdasarkan hasil penelitian menggunakan analisis deskriptif, didapatkan hasil bahwa sikap kewirausahaan dalam kategori sedang sesuai dengan skor $63,5 \%$ dan niat berwirausaha berada dalam kategori sedang dengan skor $65,3 \%$.

Orisinalitas/Nilai - Perbedaan penelitian ini dengan penelitian sebelumnya adalah objek yang dikaji pada kalangan mahasiswi angkatan 2014 di UPI Bandung yang telah mengontrak dan lulus mata kuliah Kewirausahaan, pengukuran sikap kewirausahaan melalui dimensi Theory Planned of Behaviour (TPB) Icek Azjen tahun 1991 mengenai autonomy \& authority, economics opportunity, self realization, dan perceived confidence.
\end{abstract}

Kata Kunci: Kewirausahaan, Sikap Kewirausahan, Autonomy \& Authority, Economics Opportunity, Self Realization, Perceived Confidence, Niat Berwirausaha.

Jenis Artikel: Survei

\begin{abstract}
Purpose - The purpose of this study is to see the description of entrepreneurial attitude and entrepreneurship intention.

Design/Methodology/Approach - The design of this study is cross sectional by using descriptive approach with explanatory survey method and total of 145 respondents. A questionnaire was used as a research instrument to collect data from respondents. Analytical technique used is descriptive technique by using frequency distribution.

Findings - Based on the results of the research using descriptive analysis, the results obtained that the entrepreneurial attitude is in the medium category with a score of representative 63,5\% and entrepreneurship intention is in the medium category with a score of representative 65,3\%.

Originality/Values - The difference of this study with previous research is on the object studied at female students 2014 in UPI Bandung who have pass studied Entrepreneurship studied, the measurement of entrepreneurship attitude through the dimension of Theory Planning Behavior (TPB) Icek Azjen in 1991 about autonomy \& authority, opportunity economy, self-realization, and perceived self-confidence.
\end{abstract}

Keywords: Entrepreneurship, Entrepreneurial Attitudes, Autonomy \& Authority, Economic Opportunity, Self Realization, Entrepreneurship Intention.

Article Type: Survey 


\section{PENDAHULUAN}

Penerapan kewirausahaan di negara maju dan berkembang telah diakui mampu untuk menghadapi tantangan besar dari globalisasi seperti pembangunan sosial, persaingan, dan krisis ekonomi (Shah \& Ali, 2013:217). Penciptaan bisnis baru untuk perluasan lapangan kerja mampu menjadi mesin penggerak produktivitas ekonomi negara (Botsaris \& Vamvaka, 2014:3). Tidak hanya dipandang sebagai cara untuk membangun bisnis, kewirausahaan juga penting untuk membangun individu agar dapat bertindak secara kreatif dan inovatif serta peka terhadap perubahan lingkungannya (Oyeumi \& Adeniyi, 2013:129).

Ketercapaian jumlah wirausaha Indonesia meski berada di atas batas minimal, namun masih rendah jumlahnya dibandingkan dengan negara lain seperti Singapura 7\%, Malaysia 5\%, dan Thailand 4\%. Ditegaskan David Mc Clelland, Menggiatkan intensi kewirausahaan mahasiswa dengan program pengajaran dan pembinaan kewirausahaan dapat meningkatkan pertumbuhan ekonomi serta cara untuk menghadapi pasar bebas ASEAN (Kusuma, Warmika \& Wirananda, 2016:678). Pertumbuhan wirausaha Indonesia berpotensi terus meningkat dengan dukungan berbagai pihak di mana wirausaha dari kalangan lelaki dewasa Indonesia memiliki kesempatan dan kemampuan berwirausaha lebih tinggi daripada kalangan perempuan. Namun jumlah perempuan yang memulai usaha lebih banyak daripada lelaki (bisnis.tempo.com).

Pemerintah Indonesia telah mendorong tumbuhnya aktivitas kewirausahaan di lingkungan universitas melalui pendidikan Kewirausahaan, karena melihat partisipasi perempuan dalam angkatan kerja yang terus mengalami peningkatan dari $48,87 \%$ atau 12,7 juta orang pada tahun 2016 menjadi $55,04 \%$ atau 14,3 juta orang pada tahun 2017 (ekbis.sindonews.com). Berkaitan dengan hal itu, penelusuran jumlah wanita pengusaha dari kalangan mahasiswi perlu dilakukan karena aktivitasnya yang tidak selalu nampak serta untuk menggambarkan banyaknya jumlah mahasiswi yang menjalankan bisnisnya bersamaan dengan aktivitas kuliah karena secara umum wanita pengusaha di Indonesia hanya dikenal dari kalangan ibu rumah tangga (Diahsari, Sumantri, Harding, \& Sulastiana, 2015:110). Menurut survei dari berita online, satu dari sepuluh jurusan perguruan tinggi yang banyak diminati perempuan yaitu di bidang keguruan (forum.liputan6.com). Universitas Pendidikan Indonesia (UPI) merupakan lembaga pendidikan tinggi negeri yang berbasis pendidikan satu-satunya di Jawa Barat dan terbukti jika jumlah mahasiswi di UPI Bandung jumlahnya selalu lebih tinggi daripada jumlah mahasiswa.
Berdasarkan Renstra UPI tahun 2016 yang berkaitan dengan kajian masalah karir pada mahasiswanya yaitu jika para lulusan UPI banyak yang menunggu masa kerja sekitar 2 tahun bahkan lebih dan tidak memiliki kegiatan produktif baik melanjutkan sekolah, bekerja, atau membangun usaha sendiri selama masa tunggunya. Hal ini diakibatkan niat untuk berwirausaha para lulusan masih tergolong rendah.

Berbagai upaya dilakukan untuk menumbuhkan niat berwirausaha, terutama merubah pemikiran para pemuda yang selama ini hanya berniat sebagai pencari kerja (job seeker) setelah menyelesaikan sekolah atau kuliah mereka agar menjadi pencipta lapangan kerja (job maker) (Lawan, 2015:230). Dalam menghadapi permasalahan pembangunan, pendidikan tinggi tidak sekedar dituntut proaktif berpartisipasi dalam pembangunan jangka pendek, tetapi juga harus memberikan perhatian yang mendalam pada etika dan moral yang luhur seperti mendidik mahasiswanya untuk berprinsip hidup wirausaha (Laguador, 2013:29).

Prinsip model niat ditentukan oleh sikap, individu yang memandang sikap kewirausahaan menguntungkan akan meningkatkan niat untuk melaksanakan kegiatan kewirausahaan (Botsaris \& Vamvaka, 2014:4). Penelitian yang telah dilakukan mengenai niat berwirausaha di kalangan mahasiswa Indonesia mengindikasikan permasalahan karakteristik individu yang hampir sama, dengan dipengaruhi faktor sikap kewirausahaan ketertarikan untuk berkarir pada bidang kewirausahaan atau bisnis menjadi meningkat (Sutanto, 2014; Santoso \& Oetomo, 2016).

Menggiatkan intensi kewirausahaan mahasiswa dengan program pengajaran dan pembinaan kewirausahaan dapat meningkatkan pertumbuhan ekonomi serta cara untuk menghadapi pasar bebas ASEAN (Kusuma, Warmika \& Wirananda, 2016:678). Pemahaman potensi serta pengenalan bidang wirausaha sebagai karir mahasiswa dapat membantu dalam pembentukan niat berwirausaha (Kadiyono, 2014:27)

Tujuan dari penelitian ini adalah untuk mengetahui gambaran sikap kewirausahaan dan niat berwirausaha.

\section{KAJIAN PUSTAKA \\ Kewirausahaan}

Ilmu kewirausahaan bagi setiap individu mampu memberikan kontribusi dan fungsi yaitu, mampu mengubah hidup individu dengan mendidik sikap dan pikirannya agar dapat bertindak secara kreatif dan inovatif (Oyeumi \& Adeniyi, 2013:129) serta dapat berperan dalam interaksi dengan lingkungan masyarakat yang 
dinamis (Rosqiue, 2011:454). Wirausaha merupakan potensi yang baik dalam pembangunan, baik dalam jumlah maupun mutu dari wirausaha yang diciptakan (Pratiwi \& Wardana, 2016:5219).

Diperkenalkan oleh Richard Cantillon pada tahun 1755, entrepreneurship berawal dari bahasa Perancis yaitu 'entreprende' yang berarti petualang, pencipta, dan pengelola usaha. Kemampuan seorang wirausaha secara khusus ditujukan untuk menciptakan dan menumbuhkan organisasi melalui identifikasi dan pembangunan pada suatu peluang disebut kewirausahaan (Maas \& Jones, 2017:5). Kewirausahaan sebagai promotor pembangunan ekonomi dari sudut manajemen bisnis dipandang sebagai cara pemenuh kebutuhan dengan mengenali peluang usaha, mempersiapkan sumber daya dan menciptakan kegiatan bisnis (Ghayazi, Omidian, \& Hosseinpoor, 2014:52). Penciptaan bisnis baru melalui pemanfaatan pengetahuan dan teknologi universitas, dapat memberikan kontribusi terhadap pertumbuhan produktivitas di masyarakat (Juan Carlos., 2017:66) berupa inovasi dan penciptaan lapangan kerja dengan perubahan konsep ekonomi dan sosial yang dinamis (Ibrahim \& Mas'ud, 2016:226).

\section{Psychological Entrepreneurship}

Terdapat enam teori kajian kewirausahaan, di antaranya: 1) Anthropological Entrepreneurship, 2) Economic Entrepreneurship, 3) Opportunity-Based Entrepreneurship, 4) Psychological Entrepreneurship, 5) ResourceBased Entrepreneurship, dan 6) Sociological Entrepreneurship. (Simpeh, 2011:1). Teori psikologi mencoba menjawab karakteristik perorangan yang membedakan wirausaha dan yang bukan wirausaha serta karakteristik perorangan yang membedakan wirausaha berhasil dan tidak berhasil. Bagian dari aspek psychological entrepreneurship yaitu social capital, entrepreneurial attitude, dan entrepreneurship strategy (Frese \& Gielnik, 2014:414-416).

\section{Sikap Kewirausahaan}

Sikap pembentuk kewirausahaan adalah pembentuk tindakan yang bergantung dengan persepsi individu dalam menilai hal-hal yang menguntungkan maupun tidak menguntungkan dari aktivitas bisnis (Ajzen, 1991:188). Sikap merupakan kemampuan menemukan dan mengevaluasi peluang-peluang usaha, mengumpulkan sumber daya yang diperlukan, dan bertindak untuk memperoleh keuntungan dari peluang-peluang usaha yang muncul (Meredith, Nelson, \& Neck, 2002:8). Sikap sebagai kecenderungan untuk berpikir atau menanggapi sesuatu dengan perasaaan dan evaluasi tentang objek berupa bisnis yang diperkuat oleh pengetahuan dan pengalaman individu (Walter,
2015:216). Sikap individu terbentuk dari serangkaian tindakan yang diyakini memberikan manfaat untuk memenuhi kebutuhan atau keinginan hidup (Anggadwita \& Dhewanto, 2016:137). (Ganarsih \& Wasnury (2015:6) mengemukakan beberapa kemampuan yang harus dimiliki oleh seorang wirausaha yaitu: 1) Self Knowledge, yaitu memiliki pengetahuan tentang usaha yang akan dilakukan atau ditekuni. 2) Imagination, yaitu memiliki imajinasi, ide, perspektif serta tidak mengandalkan kesuksesan masa lalu. 3) Practical Knowledge, yaitu memiliki pengetahuan praktis misalnya pengetahuan teknik, desain, proses pembukuan, administrasi dan pemasaran. 4) Search Skill, kemampuan menemukan, berkreasi dan berimajinasi. 5) Foresight, yaitu berpandangan jauh ke depan. 6) Computation Skills, kemampuan berhitung dan memprediksi keadaan di masa yang akan datang. 7) Communication Skills, kemampuan berkomunikasi, bergaul dan berhubungan dengan orang lain.

Unsur-unsur sikap yang terdapat dalam Theory of Planned Behaviour mencakup: 1) Autonomy and Authority atau otoritas dan otonomi berkaitan dengan kekuasaan dan kebebasan dari diri individu. 2) Economic Opportunity and Challenge atau tantangan dan peluang ekonomi sebagai suatu kondisi yang muncul berupa pekerjaan yang menantang dan memiliki nilai ekonomi tinggi jika dapat dimanfaatkan oleh individu kreatif. 3) Security and Work load atau keamanan dan beban kerja merupakan kondisi kerja yang aman dan tidak membebankan tugas yang melebihi dari kemampuan individu, sehingga individu berada pada zona nyamannya 4) Avoid Responsibility atau menghindari tanggungjawab dari pekerjaan yang tinggi resikonya, 5) Self realization and participation atau partisipasi dan realisasi diri mencerminkan aktivitas individu yang berdaya cipta kreatif dan mampu diterapkan sebagai pemenuh kebutuhan kondisi lingkungannya. 6) Social Environment and Career atau karir dan lingkungan sosial sebagai unsur yang mempengaruhi individu untuk memilih pekerjaan yang menghasilkan manfaaat dan mendukung perkembangan lingkungan sekitarnya. 7) Perceived Confidence, atau keyakinan pada kemampuan diri merupakan pandangan individu yang percaya diri mampu menjalankan proses bisnis dan mendukungnya untuk berkembang. (Ajzen, 1987; 1991:7-10; Davidsson, 1995:6-8; Gurbuz \& Aykol, 2008:49; Suharti, 2011:126; Sidharta \& Sidh, 2013; Azwar, 2013:121, Wijayanti \& Suryani, 2016:7).

Dimensi sikap kewirausahaan menurut Meredith, Nelson, \& Neck (2002:3) yaitu: 1) Self confident, 2) Task result oriented, 3) Risk taker, 4) Leadership, 5) Originality, dan 6) Future oriented. 
Big five personality traits dikenal sebagai pembentuk karakteristik wirausaha yang terdiri dari elemen: 1) Agreebleness, 2) Openness to experience, 3) Extraversion, 4) Conscientiousness dan 5) Neuroticism (Niranjan \& Krishnakumare, 2016:330). Atribut psikologi individu untuk bertindak sebagai pengusaha membutuhkan komponen berikut: 1) Achievement, 2) Self esteem, 3) Personal control, 4) Innovation, 5) Self efficacy, 6) Self esteem, 7) Risk taking, 8) Personality traits, 9) Optimism, 10) Self confiendence (Botsaris \& Vamvaka, 2014:218; Bell, 2016; Javed, Ali, Hamid, Shahid, \& Kulosoom, 2016; Ramoni, 2016; Ngoc Khuong \& Huu An, 2016; Baluku, Kikooma, \& Kibanja, 2016; Chaudhary, 2017).

Niat Berwirausaha

Niat berwirausaha adalah keinginan dan rencana individu untuk terlibat dalam penciptaan kegiatan ekonomi baru (Davidsson, 2016:197), keyakinan diri yang diakui oleh seseorang untuk mendirikan bisnis baru secara sadar terencana yang akan dilakukan pada masa depan (Daniela Maresch, Harms, Kailer, \& Wimmer-Wurmc, 2015:2). Seperangkat set mental dari individu yang mendorong untuk penciptaan nilai guna dari usaha atau bisnis yang akan memenuhi tujuan disebut sebagai niat berwirausaha (Javed, 2016:56). Niat menggambarkan suatu kesiapsiagaan individu untuk bertindak, kesukarelaan dalam mengembangkan usaha baru, dan persepsi individu yang mampu mengatasi rintangan dan desakan (Ahmed, Jane., et al, 2017:6). Niat diartikan sebagai langkah awal proses pendirian bisnis jangka panjang dengan komitmen yang kuat dari individu yang akan menjalankan (Sumanjaya, Widajanti, \& Lamidi, 2016:434). Niat berwirausaha menunjukkan tindakan dari keinginan individu untuk terlibat dalam perilaku seorang wirausaha yang menimbulkan kinerja sesuai niat yang diupayakan (Hisrich, Peters, \& Shepherd, 2016:16). Niat berwirausaha dipahami sebagai kesediaan individu untuk melakukan perilaku wirausaha dan terlibat dalam kegiatan wirausaha atau mendirikan bisnis baru yang didasarkan pada perceived desirability dan feasibility dalam kaitannya dengan aktivitas wirausaha (Zahirah, Sidek, Ali, \& Ismail, 2016:6061).

Davidsson (2016:198-202) ditentukan oleh beberapa komponen antara lain: 1) Desire atau keinginan individu untuk terlibat melakukan kegiatan bisnis baik dalam waktu dekat maupun jangka waktu lama. Beberapa faktor yang mempengaruhi keinginan kalangan wanita untuk berbisnis yaitu a) Personal characteristics, b) Jalur keadaan kehidupan merupakan kondisi untuk dapat berubah karena frustasi dan kebosanan dalam bekerja yang tidak, c) Dukungan lingkungan (Love \& Ayodole, 2014:46). 2) Plan atau rencana untuk merumuskan langkah yang harus dilakukan agar ide usaha dapat dijalankan. 3) Act atau tindakan, menunjukkan ketegasan tindakan individu ketika menemukan peluang usaha. Tindakan dapat berjalan dengan adanya entrepreneurship skills meliputi perencanaan bisnis, peka terhadap peluang, analisis lingkungan bisnis dan kemapuan mengakses keahlian eksternal (Mulyadi \& Irawan, 2016:218).

Terdapat empat unsur yang mempengaruhi niat seseorang untuk berwirausaha di antaranya: 1) Desirable atau keinginan, dipahami sebagai ketertarikan individu untuk menjalankan bisnis sebagai karir yang dipengaruhi kekuatan dari dalam diri dan dorongan lingkungan individu; 2) Feasible atau kelayakan, merupakan kepercayaan terhadap kemampuan baik pengetahuan maupun pengalaman individu sendiri dalam menjalankan bisnis; 3) Ability atau kemampuan individu yang secara kreatif dapat menyambungkan informasi yang didapat dengan potensi bisnis baru; 4) Keuntungan, sebagai pencapaian usaha yang bisa diperhitungkan dari aktivitas kerja keras individu dengan hasil sesuai kebebasan individu dibandingkan dengan alternatif bekerja pada orang lain (Weber, Oser, Achtenhagen, Michael Fretschner, \& Trost, 2014:165; James, Hernandez, Mahon, \& Chee, 2016:164; Ngoc Khuong \& Huu An, 2016:106; Hisrich, Peters, \& Shepherd, 2016:16-17; Zahirah et al., 2016:62).

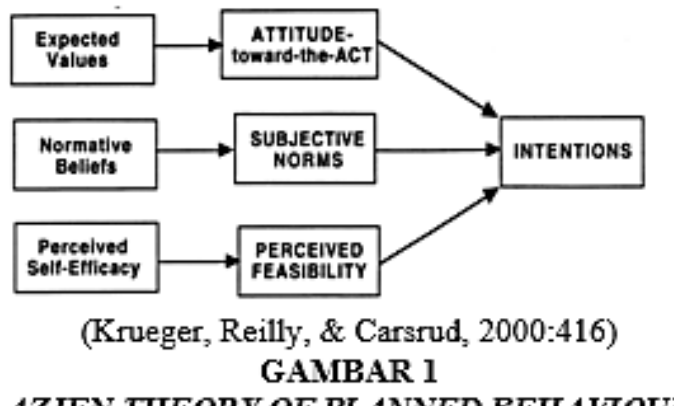

AZJEN THEORY OF PLANNED BEHAVIOUR

Theory Planned Behaviour (TPB) menyatakan secara empiris jika faktor niat dapat memprediksi suatu perilaku, sementara sikap berhasil memprediksi niat. Keterkaitan gambar di atas dengan kewirausahaan yaitu expected value atau nilai yang diharapkan akan membentuk sikap kewirausahaan. Normatif beliefs atau keyakinan normatif akan menghasilkan kepercayaan pada norma subjektif. Perceived self efficacy atau kepercayaan terhadap kemampuan diri akan menimbulkan kelayakan yang dirasakan atas pengetahuan yang dimiliki individu. Tiga unsur tersebut masing-masing memiliki pengaruh terhadap niat berwirausaha yang berbeda. Kewirausahaan sebagai perilaku disengaja akibat adanya sikap positif yang membangun dari 
individu akan menariknya untuk berkarir dalam bisnis. Semakin baik sikap dan norma subjektif berehubungan dengan suatu perilaku, maka semakin besar kontrol perilakunya (Zahirah et al., 2016:133). Memprediksi kegiatan kewirausahaan hanya dengan faktor dari luar individu seperti norma subjektif, biasanya berpengaruh kecil pada niat dan perilaku (Krueger \& Carsrud, 1993:318).

Pendidikan kewirausahaan mengacu pada cara di mana universitas menyediakan sistem dan alat yang diperlukan untuk mengajarkan penciptaan dan pengelolaan bisnis. Melalui silabus, khususnya meningkatkan pemahaman semangat kewirausahaan dan tindakan kewirausahaan dengan memberikan keterampilan administrasi atau manajemen praktis yang dibutuhkan untuk memulai usaha, mengembangkan jaringan, atau mengidentifikasi peluang. Dengan demikian, mahasiswa dapat menunjukkan kesiapan melakukan apapun untuk menjadi pengusaha profesional yang akan menciptakan dan menjalankan bisnis mereka sendiri, atau mereka bertekad untuk menciptakan bisnis di masa depan. Ringkasannya dapat dilihat pada gambar berikut.

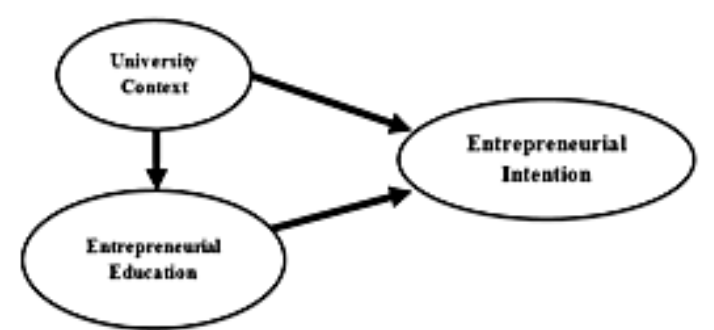

(Diaz \& Fernandez, 2017:68)

GAMBAR 2

PERAN UNIVERSITAS PADA PEMBENTUKAN NIAT BERWIRAUSAHA

\section{METODE PENELITIAN}

Penelitian ini menggunakan pendekatan kewirausahaan khususnya mengenai sikap kewirausahaan dan niat berwirausaha. Variabel bebas yang terdapat pada penelitian ini yaitu sikap kewirausahaan dengan dimensi autonomy \& authority, economics opportunity, self realization, dan perceived confidence. Sedangkan variabel terikat yaitu niat berwirausaha dengan dimensi keinginan menjadi wirausaha, perencanaan memulai usaha, dan tindakan memulai usaha.

Objek/unit analisis pada penelitian ini Universitas Pendidikan Indonesia. Penelitian ini dilakukan pada kurun waktu kurang dari satu tahun, sehingga teknik pengumpulan data yang digunakan pada penelitian ini adalah crosssectional method. Teknik penarikan sampel yang digunakan dalam penelitian ini adalah simple random sampling dengan mengambil sampel pada mahasiswi angkatan 2014 di UPI Bandung sebanyak 145orang. Teknik pengumpulan data yang digunakan adalah studi kepustakaan, observasi, wawancara, dan angket. Sedangkan teknik analisis data yang dilakukan adalah analisis deskriptif dengan menggunakan distribusi frekuensi.

\section{HASIL PENELITIAN DAN PEMBAHASAN Gambaran Sikap Kewirausahaan}

TABEL 1 REKAPITULASI VARLABEL SIKAP KEWIRAUSAHAAN

\begin{tabular}{clccc}
\hline No & \multicolumn{1}{c}{ Dimensi } & $\begin{array}{c}\text { Total } \\
\text { Skor }\end{array}$ & $\begin{array}{c}\text { Skor } \\
\text { Ideal }\end{array}$ & (\%) \\
\hline 1 & $\begin{array}{l}\text { Autonomy \& } \\
\text { Authority }\end{array}$ & 2689 & 4350 & 61,8 \\
2 & $\begin{array}{l}\text { Economics } \\
\text { Opportunity }\end{array}$ & 2202 & 3625 & 60,7 \\
3 & $\begin{array}{l}\text { SelfRealization } \\
4\end{array}$ & 1918 & 2900 & 66,1 \\
& $\begin{array}{l}\text { Perceived } \\
\text { Confidence }\end{array}$ & 1943 & 2900 & 67 \\
\hline & Total & $\mathbf{8 7 5 2}$ & $\mathbf{1 3 7 7 5}$ & $\mathbf{6 3 , 5}$ \\
\hline
\end{tabular}

Berikut penjelasan mengenai temuan penelitian dari variabel sikap kewirausahaan pada mahasiswi UPI Bandung dilihat dari perbandingan total skor pada masing-masing dimensi sebagai berikut:

Berdasarkan hasil penelitian dari angket yang disebar kepada 145 responden dapat diketahui bahwa sikap kewirausahaan mahasiswi angkatan 2014 di UPI Bandung dalam kategori sedang pada skala 7163 sampai 9367, dengan perolehan skor 8752 atau $63,5 \%$ dari skor kriterium. Skor tertinggi berdasarkan hasil jawaban responden terdapat pada dimensi perceived confidence dengan perolehan skor 1943 atau sebesar $67 \%$ dari skor ideal. Sedangkan dimensi terendah yaitu economics opportunity dengan perolehan skor 2202 atau 60,7\%. Berikut gambaran sikap kewirausahaan para mahasiswi UPI dalam garis kontinum.

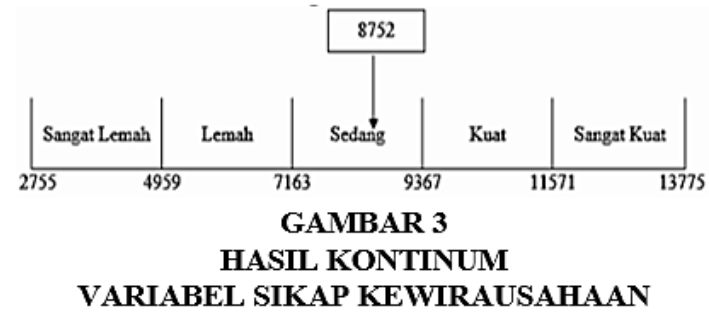

Sikap kewirausahaan para mahasiswi UPI Bandung dalam kategori sedang yang menunjukkan sikap perceived confidence sudah tertanam kuat yaitu kemampuan yang dimiliki untuk sukses sebagai wirausaha berupa pengetahuan maupun pengalaman yang pernah didapatkan selama mengikuti mata kuliah Kewirausahaan. Di mana sebagian besar mahasiswa merasa cukup puas atas pembelajaran bisnis yang didapatkannya. Pandangan individu yang percaya diri mampu menjalankan proses bisnis dan mendukungnya untuk berkembang 
(Davidsson, 1995:7). Optimis untuk sukses dengan berkarir menjadi wirausaha dan fokus pada apa yang ingin dituju merupakan sifat untuk mendapatkan kesuksesan hidup (Scarborough \& Cornwall, 2016:22-26). Berpikir kritis dibutuhkan sepanjang hidup seseorang serta dapat berkontribusi secara kreatif dalam proses belajar maupun karir seseorang (Thahara, Mulyadi, \& Utama, 2016:70).

Indikator dari perceived confidence yang masih perlu ditingkatkan yaitu kemampuan menerima ketidakamanan dari pekerjaan yang akan dijalankan seperti berbisnis. Wanita pengusaha ciri khasnya bersifat detail dalam memandang sesuatu dan memiliki kewaspadaan yang tinggi, oleh karena itu hanya wanita berkomitmen kuat yang akan berani mengambil resiko tinggi dari bisnis yang dijalankannya. Wanita memiliki tingkat pesimisme lebih tinggi ditanyakan pada pernyataan tentang peluang dan ketakutan yang lebih besar akan kegagalan (Canizares, 2013:72). Fleksibel terhadap perubahan atau mampu beradaptasi dengan lingkungan dan banyak akal untuk berstrategi menghadapi ketidakpastian situasi kehidupan bisnis harus selalu dilakukan oleh wiausaha untuk sukses (Scarborough \& Cornwall, 2016:22-26).

Aspek dimensi economics opportunity yang sudah dimiliki mahasiswi UPI yaitu peluang menemukan ide bisnis. Kemampuan yang harus dimiliki oleh wirausaha berkaitan dengan peluang yaitu imagination, search skill, computation skill, dan foresight (Ganarsih \& Wasnury, 2015:6). Tantangan hal atau objek yang menggugah tekad untuk meningkatkan kemampuan mengatasi masalah, rangsangan untuk bekerja lebih giat, dengan adanya kewirausahaan sebagai pekerjaan yang menantang dan membuka peluang ekonomi (Wijayanti \& Suryani, 2016:7). Kemudian aspek motivasi yang dimiliki untuk berbisnis. Wanita cenderung memandang melakukan bisnis kurang menguntungkan dibandingkan dengan kegiatan bisnis yang pria lakukan karena adanya batasan budaya (Gathungu \& Mwangi, 2014:120). lingkungan sosial sebagai unsur yang mempengaruhi individu untuk memilih pekerjaan yang menghasilkan manfaaat dan mendukung perkembangan lingkungan sekitarnya (Gurbuz \& Aykol, 2008:49; Suharti, 2011:126). Motivasi individu untuk menjadi wirausaha ditetapkan oleh 2 faktor yaitu: 1) Faktor internal berupa sikap individu dan persepsi dan 2) Faktor eksternal berupa lingkungan keluarga serta pelatihan dan training (Mulyadi, Tarmedi, \& Ruslandi, 2016:260). Niat berwirausaha merupakn faktor kunci dalam penciptaan usaha baru yang dipengaruhi oleh faktor luar seperti latar belakang keluarga, posisi dalam keluarga, pekerjaan keluarga, dan pendidikan (Utama, S, \& Sutarni, 2016:707).

Adapun penjelasan mengenai temuan penelitian dari variabel niat berwirausaha pada mahasiswi UPI Bandung dilihat dari perbandingan total skor pada masing-masing dimensi berikut:

TABEL 2

REKAPITULASI VARIABEL NIAT BERWIRAUSAHA

\begin{tabular}{clccc}
\hline No & \multicolumn{1}{c}{ Dimens! } & $\begin{array}{c}\text { Total } \\
\text { Skor }\end{array}$ & $\begin{array}{c}\text { Skor } \\
\text { Ideal }\end{array}$ & (\%) \\
\hline 1 & $\begin{array}{l}\text { Keinginan } \\
\text { berwirausaha }\end{array}$ & 2783 & 4350 & 64 \\
2 & $\begin{array}{l}\text { Perencanaan } \\
\text { memulai usaha }\end{array}$ & 2769 & 4350 & 63,7 \\
3 & $\begin{array}{l}\text { Tindakan } \\
\text { memulai usaha }\end{array}$ & 2500 & 3625 & 69 \\
\hline & Total & $\mathbf{8 0 5 2}$ & $\mathbf{1 2 3 2 5}$ & $\mathbf{6 5 , 3}$ \\
\hline
\end{tabular}

Berdasarkan hasil penelitian dari angket yang disebar kepada 145 responden dapat diketahui bahwa variabel niat berwirausaha dalam kategori sedang pada skala 7163 sampai 9367 dengan perolehan skor 8052 atau $63,5 \%$ dari skor kriterium. Skor tertinggi berdasarkan hasil jawaban responden terdapat pada dimensi tindakan memulai usaha (act) dengan perolehan skor sebesar 69\% dari skor ideal. Sedangkan dimensi dengan perolehan skor terendah yaitu perencanaan memulai usaha (plan) dengan skor 63,7\% dari skor ideal. Berikut gambaran niat berwirausaha para mahasiswi UPI dalam garis kontinum.

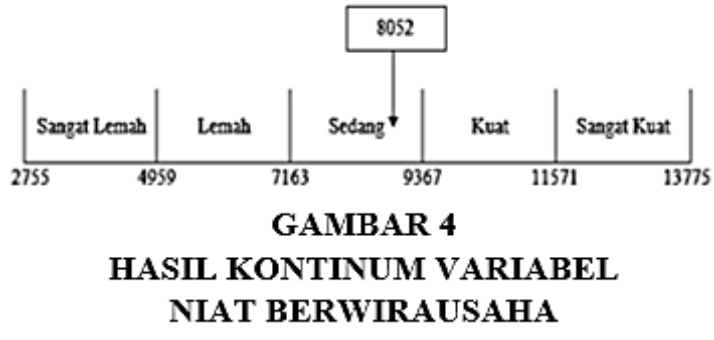

Niat berwirausaha para mahasiswi UPI Bandung dalam kategori sedang menunjukkan aspek tindakan (act) yang tinggi berupa kesiapan diri melakukan apa saja untuk berbisnis, karena ciri wanita wirausaha merupakan pembelajar yang serba ingin tahu dan serba bisa melakukan banyak kegiatan dalam satu waktu. Ketegasan diperlukan untuk melakukan tindakan ketika menemukan peluang usaha (Davidsson, 2016:198-202). Pilihan keputusan, menekankan pada kesiapan diri dan faktor pendukung lainnya untuk menindaklanjuti rencana usaha yang sudah disusun (Obschonka, Hakkarainen, Lonka, \& Salmela-Aro, 2016-67; Sumanjaya et al., 2016:438). Niat kewirausahaan akan mengembangkan seseorang merasa mampu dalam melakukan tugas atau kegiatan kewirausahaan dengan berhasil, sehingga perlu ketepatan dalam bertindak (Pfeifer, Šarlija, \& Zekic, 2014:3). Karena bagi pebisnis pemula dibutuhkan niat dan keyakinan diri untuk 
meluncurkan bisnisnya (Przepiorka, 2016:42). Pada fase prelaunch usaha faktor individu merupakan unsur yang paling berpengaruh besar pada perusahaan start up karena menentukan jalannya tindakan pengusaha (Bilgin \& Danis, 2016:5).

Indikator act terendah meskipun secara keseluruhan tinggi perlu ditingkatkan pada aspek ketertarikan mengikuti komunitas bisnis. Para mahasiswi beranggapan tidak memiliki waktu luas untuk beraktivitas di luar rumah kapan saja. Sifat dari wirausaha wanita yaitu sebagian besar melibatkan akitivitas bisnis berbasis rumah (Gathungu \& Mwangi, 2014:120). Menciptakan sebuah iklim yang menguntungkan bagi kewirausahaan seperti di lingkungan universitas akan melahirkan komunitas bisnis di lingkungan mahasiswa (Diaz \& Fernandez, 2017:68).

Aspek indikator niat berwirausaha yang secara keseluruhan perlu ditingkatkan berkaitan dengan keseriusan belajar bisnis dan mendeskripsikan operasionalisasai bisnis. Pola pikir seorang wirausaha adalah mindset proaktif, kreatif, inovatif karena pola pikir itu dibutuhkan oleh setiap orang wiraswasta untuk melakukan bisnis (Nuryanti, Tarmedi, Utama, \& Razati, 2016:700). Perencanaan bisnis adalah kegiatan yang diarahkan untuk memprediksi masa depan dan mengembangkannya sesuai tindakan. Perencanaan bisnis umumnya berupa dokumen yang membutuhkan banyak waktu untuk mempersiapkannya dan sebagai kunci aktivitas start up bagi calon pengusaha (Brinckmann \& Kim, 2015:154).

Setiap individu dapat menjadi wirausaha dengan menerapkan sikap wirausaha dalam setiap aktivitas yang dilakukannya (Setiadi \& Mawarine, 2014:147). Seorang wirausaha yang memiliki sikap di dalam usahanya adalah orang yang tidak mengenal lelah dalam berwirausha (Mulyadi, Razati, \& Ramadhanti, 2016:33). Sikap positif akan menjadi tanda yang baik dalam proses mempelajari kewirausahaan (Zulhfizh, Atmaka, 2013:15) yang akan membentuk niat untuk bertindak sukarela dalam mengembangkan aktivitas usaha baru, dan mampu mengatasi rintangan dan desakan yang dihadapi (Ahmed et al., 2017:6).

\section{KESIMPULAN}

Berdasarkan hasil penelitian yang telah dilakukan menggunakan analisis deskriptif dengan distribusi frekuensi dapat diambil kesimpulan bahwa, gambaran sikap kewirausahaan dalam kategori sedang dilihat dari perolehan skor 8752 atau $63,5 \%$ dan niat berwirausaha dalam kategori sedang dilihat dari perolehan skor 8052 atau $63,5 \%$.
Adanya penelitian ini diharapkan dapat membantu peneliti berikutnya dalam melakukan penelitian mengenai sikap kewirausahaan dan niat berwirausaha dengan menggunakan indikator yang berbeda dari sumber teori yang lebih beragam, dan terhadap objek yang berbeda. Karena masih banyaknya keterbatasan dalam penelitian ini, khususnya yang berkaitan dengan metode penelitian dan teknik pengumpulan data.

\section{DAFTAR PUSTAKA}

Ahmed, T., Jane, V. G. R. C., Ahmed, T., \& Klobas, J. (2017). Specialized Entrepreneurship Education: Does It Really Matter? Fresh Evidence From Pakistan. International Journal of Entrepreneurial Behaviour, 23(1), 4-19.

Ajzen, I. (1987). Attitudes, Traits, and Actions: Dispositional Prediction of Behaviour in Personality and Social Psychology. In Advance in Experimental Social Psychology (Vol. 20, pp. 1-63).

Ajzen, I. (1991). The theory of planned behavior. In Orgnizational Behavior and Human Decision Processes (Vol. 50, pp. 179-211). https://doi.org/10.1016/07495978(91)90020-T

Anggadwita, G., \& Dhewanto, W. (2016). The Influence of Personal Attitude and Social Perception On Women Entrepreneurial Intentions in Micro and Small Enterprises in Indonesia. International Journal of Entrepreneurship and Small Business, 27(23), 131-148. https://doi.org/10.1504/IJESB.2016.073974

Azwar, B. (2013). Analisis Faktor-faktor yang Mempengaruhi Niat Kewirausahaan (Entrepreneurial Intention) (Studi terhadap Mahasiswa Universitas Islam Negeri SUSKA Riau ). Jurnal Kewirausahaan, 12(1), 12-22.

Baluku, M. M., Kikooma, J. F., \& Kibanja, G. M. (2016). Psychological Capital and The Startup Capital Entrepreneurial Success Relationship. Journal of Small Business \& Entrepreneurship, 28(1), 27-54. https://doi.org/10.1080/08276331.2015.1132 512

Bell, R. (2016). An Assessment of The Relationship Between Entrepreneurial Attitudes and Likelihood of Graduate Employment in A Professional Field. Education \& Training, 58(1), 2-17.

Bilgin, M. H., \& Danis, H. (2016). Entrepreneurship, Business and Economics Vol . 1 Proceedings of the 15th Eurasia Business and Economics Society Conference (Vol. 1). Londond: Springer.

Botsaris, C., \& Vamvaka, V. (2014). Attitude 
Toward Entrepreneurship: Structure, Prediction from Behavioral Beliefs, and Relation to Entrepreneurial Intention. Journal Knowledge Economy, 1(11), 1-28.

Brinckmann, J. A. N., \& Kim, S. M. I. N. (2015). Why We Plan: The Impact of Nascent Entrepreneurs Cognitive Characteristics and Human Capital on Business Plannis. Strategic Entrepreneurship Journal, 166(9), 153-166.

Canizares, S. (2013). Gender and Entrepreneurship: Analysis of A Young University Population. Journal Economics Studies, 13(1), 67-78.

Chaudhary, R. (2017). Demographic Factors, Personality and Entrepreneurial Inclination A Study Among Indian University Students. Education \& Training, 59(2), 171-187.

Davidsson, P. (1995). Determinants of Entrepreneurial Intentions. Journal of Entrepreneurship in Emerging Economies, $1(1), 1-31$.

Davidsson, P. (2016). Researching Entrepreneurship Conceptualization and Design Second Edition. Management (Second, Vol. 16). Springer International Publishing Switzerland. https://doi.org/Article

Diahsari, E. Y., Sumantri, S., Harding, D., \& Sulastiana, M. (2015). Memaknai Keberhasilan Usaha: Studi pada Perempuan Pengusaha di Yogyakarta. Jurnal Psikologi \& Kemanusiaan, 1(1), 978-979.

Diaz, J. C., \& Fernandez, A. (2017). The Influence of University Context on Entrepreneurial Intentions. In Change: The Magazine of Higher Learning (Vol. 32, pp. 65-81). https://doi.org/10.1007/978-3-319-47949-1

Frese, M., \& Gielnik, M. M. (2014). The Psychology of Entrepreneurship. Journal of Psychology and Business, 1(1), 413-438. https://doi.org/10.1146/annurev-orgpsych031413-091326

Ganarsih, R. L., \& Wasnury, R. (2015). The Influence of Attitude and Contextual Factor to The Ability of Entrepreneurship in School of Economics Dharma Putra Pekanbaru. Jurnal Kewirausahaan, 1(1), 1-18.

Gathungu, J. M., \& Mwangi, P. W. (2014). Entreprenuerial Intention, Culture, Gender and New Venture Creation: Critical Review. Entrepreneurship Journal, 4(2), 112-132.

Ghayazi, S., Omidian, F., \& Hosseinpoor, M. (2014). Factors affecting entrepreneurship of educational management students in Andimeshk Payame Noor. Social and HUmanistic Science, 21(1), 51-61. https://doi.org/10.18052/www.scipress.com/ ILSHS.21.51
Gurbuz, G., \& Aykol, S. (2008). Entrepreneurial Intentions of Young Educated Public in Turkey. Journal of Global Strategic Management, 2(2), 47-56. https://doi.org/10.20460/JGSM.2008218486

Hisrich, R. D., Peters, M. P., \& Shepherd, D. A. (2016a). Entrepreneurship Tenth Edition.

Hisrich, R. D., Peters, M., \& Shepherd, D. A. (2016b). Tenth Edition Entrepreneurship. U.S.A: Mc Graw Hill Education.

Ibrahim, N. A., \& Mas'ud, A. (2016). Moderating Role of eEntrepreneurial Orientation on The Relationship Between Entrepreneurial Skills, Environmental Factors and Entrepreneurial Intention: A PLS Approach. In Management Science Letters (Vol. 6, pp. 225-236). https://doi.org/10.5267/j.msl.2016.1.005

James, M., Hernandez, E., Mahon, C., \& Chee, L. K. (2016). Entrepreneurial Intentions of University Students in An Emerging Economy The Influence of University Support and Entrepreneurial Intention. Journal of Entrepreneurship in Emerging Economies, $8(2), \quad 162-179$. https://doi.org/10.1108/JEEE-10-2015-0058

Javed, F. (2016). Role of Social Networks , Emotional Intelligence and Psychosocial characteristics in developing Entrepreneurial Intentions of Students. Journal of Business and Management, 3(1), 54-81.

Javed, F., Ali, R., Hamid, A., Shahid, M., \& Kulosoom, K. (2016). Role of Social Networks , Emotional Intelligence and Psychosocial characteristics in developing Entrepreneurial Intentions of Students. Sukkur IBA Journal of Management and Business, 3(1), 54-81.

Juan Carlos Díaz-Casero, Antonio FernándezPortillo, Mari-Cruz Sánchez- Escobedo, and R. H.-M. (2017). The Influence of University Context on Entrepreneurial Intentions. In Entrepreneurial Universities, Innovation, Technology, and Knowledge Management (pp. 65-81) https://doi.org/10.1007/978-3-319-47949-1

Kadiyono, A. L., Psikologi, F., \& Padjadjaran, U. (2014). Efektivitas pengembangan potensi diri dan orientasi wirausaha dalam meningkatkan sikap wirausaha effectiveness of self development and entrepreneurial orientation in improving entrepreneurial attitude. Jurnal Intervensi Psikologi, 6(1), 25-38.

Krueger, N. F., \& Carsrud, A. L. (1993). Entrepreneurial Intentions: Applying The Theory of Planned Behaviour Entrepreneurial Intentions: Applying The Theory of Planned Behaviour. In Entrepreneurship \& Regional Development 
(pp.

$315-330)$

https://doi.org/10.1080/08985629300000020

Kusuma, M. W. A., \& Warmika, I. G. K. (2016). Analisis Faktor-faktor yang Mempengaruhi Intensi Berwirausaha pada Mahasiswa FEB S1 FEB Unud. Jurnal Manajemen, 5(1), $678-705$

Laguador, J. M. (2013). Developing Students Attitude Leading Towards A Life Changing Career. Educational Research International, 1(3), 28-33.

Lawan, U. M. (2015). Perceptions and Attitude towards Entrepreneurship Education Programme, and Employment Ambitions of Final Year Undergraduate Students in Kano, Northern Nigeria 1 2. Journal of Education and Research, 3(11), 229-242.

Love, C., \& Ayodole, M. (2014). Determining Women Entrepreneurial Motivation: A Review of Theoritical Models. Journal of Small Business \& Entrepreneurship Research, 2(3), 43-54.

Maas, G., \& Jones, P. (2017). Entrepreneurship Centres Global Presprectives on their Contributions to Higher Education Institutions. Switzerland: Palgrave Macmillan.

Maresch, D., Rainer, H., Kailer, N., \& Birgit, W.W. (2015). The Impact of Entrepreneurship Education On The Entrepreneurial Intention of Students in Science and Engineering Versus Business Studies University Programs. Technological Forecasting \& Social Change, 3(3), 1-8.

Meredith, G. G., Nelson, R. E., \& Neck, P. A. (2002). The Practice of Entrepreneurship. International Labour Office Geneva.

Mulyadi, H., \& Irawan, A. (2016). Pengaruh Keterampilan Wirausaha terhadap Keberhasilan Usaha ( Studi Kasus pada Distro Anggota Kreative Independent Clothing Kommunity di Kota Bandung ). Journal of Business and Entrepreneurship Education, 1(1), 213-223.

Mulyadi, H., Razati, G., \& Ramadhanti, D. (2016). Pengaruh Status Sosial Ekonomi Orang Tua terhadap Sikap Kewirausahaan. Journal Pendidikan Manajemen Bisnis, 11(20), 3237.

Mulyadi, H., Tarmedi, E., \& Ruslandi, G. (2016). Analysis of Factors Influencing the Student's Interests to Participate in Entrepreneurial Student Program. Advance in Econommics, Business, and Management Research, 15, 694-699.

Ngoc Khuong, M., \& Huu An, N. (2016). The Factors Affecting Entrepreneurial Intention of the Students of Vietnam National University - A Mediation Analysis of
Perception toward Entrepreneurship. Journal of Economics, Business and Management, $4(2)$, 104-111. https://doi.org/10.7763/JOEBM.2016.V4.37 5

Niranjan, S., \& Krishnakumare, B. (2016). Personality Traits and Entrepreneurial Intention Among Management and Horticultural Students of A Public University - Comparative Analysis. Journal of Scientific Research, 5(10), 330-331.

Nuryanti, B. L., Tarmedi, E., Utama, R. D. H., \& Razati, G. (2016). Growing Up Entrepreneurial Mindset with Discovery Learning Model Development. Advance in Econommics, Business, and Management Research, 15, 700-705.

Obschonka, M., Hakkarainen, K., Lonka, K., \& Salmela-Aro, K. (2016). Entrepreneurship As A Twenty-First Century Skill: Entrepreneurial Alertness and Intention in The Transition to Adulthood. In Small Business Economics (pp. 1-15). Springer US. https://doi.org/10.1007/s11187-0169798-6

Oyeumi, \& Adeniyi. (2013). Assessing Attitude To and Knowledge of Entrepreneurship Among Students with Hearing Impairment in Nigeria. Multidisciplinary Journal, 7(30), 127-142.

Pfeifer, S., Šarlija, N., \& Zekić Sušac, M. (2014). Shaping the Entrepreneurial Mindset: Entrepreneurial Intentions of Business Students in Croatia. Journal of Small Business Management, 1(1), 1-16. https://doi.org/10.1111/jsbm.12133

Pratiwi, Y., \& Wardana, I. M. (2016). Pengaruh Faktor Internal dan Eksternal terhadap Niat Berwirausaha Mahasiswa Fakultas Ekonomi dan Bisnis Universitas Udayana. Jurnal Manajemen, 5(8), 5215-5242.

Przepiorka, A. (2016). What Makes Successful Entrepreneurs Different in Temporal and Goal Commitment Dimensions? Time \& Society, 25(1), 40-60. https://doi.org/10.1177/0961463X15577264

Ramoni, S. A. (2016). Determinants of Entrepreneurial Intention among Nigerian University Graduates Ramoni. Journal of Social Sciences, 6(1), 45-59.

Rosqiue, M. (2011). Entrepreneurial Attitudes: An Empirical Analysis In Secondary Education Studentd. Journal of Business, 451-465.

Santoso, S., \& Oetomo, B. S. D. (2016). Pengaruh karateristik psikologis, sikap berwirausaha, dan norma subyektif terhadap niat berwirausaha. Jurnal Psikologi Kewirausahaan, 20(03), 338-352.

Scarborough, N. M., \& Cornwall, J. R. (2016). 
Essential of Entrepreneurship and Small Business Management (Eight Edit). England: Pearson.

Setiadi, N. J., \& Mawarine, D. (2014). Empirical Study on Entrepreneurial Attitudes and Intentions Among Indonesian Business Students. Journal of Management, 1(1), 145-162.

Shah, N., \& Ali, B. (2013). Investigating Attitudes and Intentions among Potential Entrepreneurs of a Developing Country: A Conceptual Approach. Journal of Business, 217-220.

Sidharta, I., \& Sidh, R. (2013). Analisis Faktorfaktor Sikap yang Membentuk Niat Mahasiswa Menjadi Teknopreneur. Jurnal Computech \& Bisnis, 7(2), 117-127.

Simpeh, K. N. (2011). Entrepreneurship Theories and Empirical Research: A Summary Review of The Literature. Journal of Business and Management, 3(6), 1-9.

Suharti, L. (2011). Faktor-Faktor yang Berpengaruh Terhadap Niat Kewirausahaan (Entrepreneurial Intention ) (Studi terhadap Mahasiswa Universitas Kristen Satya Wacana, Salatiga ). Jurnal Manajemen Dan Kewirausahaan Dan Kewirausahaan, 13(2), 124-134.

Sumanjaya, W., Widajanti, E., \& Lamidi. (2016). Pengaruh Karakteristik Kewirausahaan terhadap Niat Berwirausaha Pada Mahasiswa Fakultas Ekonomi Unisri dengan Motivasi Berwirausaha Sebagai Variabel Moderasi. Jurnal Ekonomi Dan Kewirausahaan, 16(3), 433-441.

Sutanto, E. M. (2014). The Study of Entrepreneurial Characteristics with Achievement Motivation and Attitude As The Antecendent Variables. Journal of Arts, Science \& Commerce, 5(4), 125-134.

Thahara, I. P., Mulyadi, H., \& Utama, R. D. H. (2016). Efektivitas. Journal of Business Management Education, 1(2), 70-74.

Utama, R. D. H., S, B. L. N., \& Sutarni, N. (2016).
Entrepreneurship Intention to Trigger Entrepreneurship Orientation. Journal Business and Management Research, 15(1), 706-710.

Walter, C. (2015). Arts Management An Entrepreneurial Approach. Book (Vol. 1). New York: Taylor \& Francis. https://doi.org/10.1017/CBO9781107415324 .004

Weber, S., Oser, F. K., Achtenhagen, F., Michael Fretschner, \& Trost, S. (2014). Becoming an Entrepreneur. Netherlands: Sense Publisher.

Wijayanti, N. G. P. P., \& Suryani, A. (2016). Perbandingan Faktor-faktor yang Mempengaruhi Intensi Berwirausaha Mahasiswa FEB Unud dan Mahasiswa Feb Undiknas. Jurnal Manajemen, 5(3), 16821712.

Zahirah, N., Sidek, M., Ali, S. M., \& Ismail, M. (2016). Proceedings of The ASEAN Entrepreneurship Conference 2014. Singapore: Springer.

Zulhfizh, Atmaka, S. (2013). Kontribus Sikap danMotivasi Belajar Siswa Terhadap Hasil Belajar. Jurnal Pembelajaran, 1(2), 13-26.

https://bisnis.tempo.co/read/news/2017/02 /09/089844576/survei-wanita-lebihberani-jadi-pengusaha-dibandingpria

https://ekbis.sindonews.com/read/120526 9/34/menaker-perempuan-makinberkontribusi-tingkatkan-ekonomiri-1494840256

http://forum.liputan6.com/t/jurusan-yangprospek-kerjanya-untukwanita/88712

http://www.upi.edu/main/file/d8030pedoman-penyusunan-rkat2017.pdf 02/01/2017 08.00 WIB 